\title{
Understanding the Experiences of First-Generation Medical Students: Implications for a Diverse Physician Workforce
}

\author{
Ruby Romero ${ }^{1} \cdot$ Karen Miotto $^{2} \cdot$ Alejandra Casillas $^{2} \cdot$ Jesse Sanford $^{3}$
}

Received: 31 October 2019 / Accepted: 7 April 2020 /Published online: 12 May 2020

(C) Academic Psychiatry 2020

Calls for a diverse physician workforce continue to grow, and a key approach to answering these calls lies in ensuring that first-generation (First Gen) undergraduate students are able to become medical students and, eventually, physicians. The Association of American Medical Colleges (AAMC) defines First Gen individuals applying for medical school as candidates "whose parents have not earned an associate's degree or higher" [1]. Although a large proportion of First Gen students in health professions are also underrepresented minority (URM) students, it is important to note that First Gen students come from different racial and ethnic backgrounds, and differ in regard to socioeconomic and immigration statuses [2]. Moreover, the obstacles faced by students differ depending on students' backgrounds. For instance, URM First Gen students face different issues (e.g., ethnic and racial biases) than non-URM First Gen students.

Published reports have indicated that $51 \%$ of First Gen undergraduate students are from minority backgrounds, while only $30 \%$ of non-First Gen undergrads are from minority backgrounds [3]. In addition, 27\% of First Gen undergraduate students reported parental incomes of less than $\$ 20,000$, while only $6 \%$ of non-First Gen undergrads reported the same [3]. Additionally, $46 \%$ of First Gen undergraduates are not US citizens [4]. In addition to diverse backgrounds, advantages that First Gen students bring to the institutions they attend include personal qualities, such as grit, innovative thinking, and insight into health disparities [5]. While this information on undergraduate First Gen students is valuable, it does not reveal the trajectories of First Gen undergraduates who become medical students.

Karen Miotto

kmiotto@mednet.ucla.edu

Grinnell College, Grinnell, IA, USA

David Geffen School of Medicine at UCLA, Los Angeles, CA, USA

3 University of California, Los Angeles, CA, USA
Difficulties in studying the First Gen population are due, in part, to historical reports' infrequent use of the term "first-generation" and conflation of demographic identifiers. Past research has used terms like "underrepresented minority," "low socioeconomic status," "disadvantaged," "at-risk," and "vulnerable" to describe First Gen students and since these terms were often used as proxies for First Gen status, many historical details on this group went uncaptured. However, more recently, accrediting organizations have begun advising medical schools on how to collect information on First Gen applicants [6]. For instance, beginning in 2017, the AAMC introduced a "First Generation College Student Indicator" on the American Medical College Application Service [1, 5]. The AAMC has also encouraged medical schools to undertake "holistic reviews" that allow admissions committees to give equal consideration to the experiences, attributes (including First Gen status), and metrics of medical school applicants [6]. Since medical schools are increasingly collecting information on their First Gen populations and considering this metric for admission into medical school, residencies, and fellowships, the need for data on First Gen individuals in medical training is a priority for medicine and academia.

The specific aims of this commentary are the following: (a) to identify educational challenges unique to the First Gen population and (b) to highlight how First Gen status among physicians can diversify the physician workforce and positively impact healthcare. While URM and First Gen students often share similar life experiences that can help diversify the physician workforce, the First Gen narrative is the primary focus of this commentary. This piece highlights initiatives aimed at diversifying the medical school pipeline and increasing matriculation for First Gen students. This commentary also advocates for research on the First Gen medical student population and illustrates the unique role that academic psychiatrists have in supporting the First Gen physician workforce. 


\section{Obstacles Start at the Undergraduate College Level}

Research indicates that First Gen undergraduates encounter challenges with the following: understanding the college process, financing college, finding a community while at school, balancing family obligations with school, and navigating college while lacking cultural capital $[7,8]$. Although cultural capital is domain specific, Oldfield defines it as the "knowledge, skills, education, and other advantages a person has that make the educational system a comfortable, familiar environment in which [a student] can succeed easily" [7]. In light of the aforementioned obstacles, various pipeline programs aimed at increasing the matriculation of educationally and financially disadvantaged medical students, including those with URM and First Gen backgrounds, have been created.

Examples of such programs at our institution are the Robert Wood Johnson Foundation-funded Summer Health Professions Education Program (SHPEP), which was launched in 1989 [9], and the Pre-Medical/Pre-Dental Enrichment Program (PREP), which admitted its charter class in 1982 [10]. The focus of SHPEP is to recruit community college students that identify with a group that is racially or ethnically underrepresented in the health professions and introduce these students to healthcare issues that affect medically underserved communities. In addition, students receive health professions school admissions counseling [11]. The focus of PREP is to prepare students from "disadvantaged backgrounds" for the MCAT or DAT exam, provide career guidance, and allow students the opportunity to observe health professionals in the field through clinical preceptorships [10]. Reports on these programs frequently classified students as "disadvantaged," rather than First Gen, and as a result, it remains unclear how many First Gen students in these and other pipeline programs have participated. However, past publications have noted PREP's overall accomplishments: $81 \%$ of PREP participants have been admitted to a health professional school [12] and 91\% of PREP alumni are active in healthcare professions [10]. In addition, our institution has experienced a $300 \%$ increase in enrollment of minority dental school applicants as a result of operating pipeline programs [13].

\section{What We Know About the First Gen Medical Student Experience}

The obstacles faced by First Gen medical students are likely to impact their health and well-being. In 2013, the AAMC piloted the Medical Student Life Survey (MSLS), which was administered to all second-year medical students at 136 US medical schools. The survey measured self-rated well-being and perceptions of the learning climate [14]. Study results indicated increased levels of stress, fatigue, and financial worries, as well as lower quality of life and social support ratings among First Gen medical students as compared with the total population. More recent mental health research on First Gen medical students found that scores for physical, psychological, and social quality of life were lower, albeit non-significantly, among First Gen students than non-First Gen students, while scores for environmental quality of life and self-care were significantly lower among First Gen students. In addition, compared with their non-First Gen peers, First Gen medical students reported lower levels of faculty role models engaging in self-care and lower levels of school support for family and personal responsibilities [5].

\section{Drop-off in First Gen Higher Education Trajectories}

Notably, as recently as 2012, only $4 \%$ of First Gen students enrolled in a doctoral or professional program (beyond a master's degree), compared with $10 \%$ of students whose parents earned a bachelor's degree [15]. When considering the fact that nearly a third of undergraduate students are First Gen, the low enrollment of First Gen students in graduate studies is alarming, as it indicates that many college-educated First Gen students are unable to progress through the medical education pipeline [16]. Possible explanations for this trend include high costs associated with pursuing medical education, varying levels of academic preparedness, a lack of cultural capital, and unsupportive institutional policies and cultures $[15,17]$. Although the cited research provides some insight, there remains a paucity of information pertaining to the decline in First Gen student enrollment in doctoral or professional programs. Studies that (a) qualitatively collect information on First Gen students who graduate from medical school and (b) identify shared factors that affect graduation rates and academic trajectories are critical in identifying barriers to medical school application and enrollment, as well as factors that precipitate attrition.

\section{First Gen Physician Attributes and Patient Care}

A diverse class of First Gen medical students has the potential to enhance medical education and training for all future physicians, improve the quality of patient care, and help address the mitigation of health disparities [18, 19]. Past research has shown that First Gen undergraduate students are more resilient than their non-First Gen peers [20] and when asked about factors that enabled them to persevere in college, First Gen undergrads identified determination, persistence, and resilience as advantageous personal strengths [21]. In addition, First Gen undergraduate students considered their academic 
pursuits in the context of others and even recalled setting aside personal interests for the greater good, effectively putting others above themselves [21]. The personal experiences of First Gen physicians and authors KM and AC are consistent with the undergraduate First Gen literature.

Although, to our knowledge, no studies quantitatively compare outcomes of patients treated by First Gen physicians to patients treated by non-First Gen physicians, a growing body of literature has shown that patients' health outcomes are generally better when more diverse healthcare teams are involved with the provision of care [18]. In addition to better health outcomes, diverse healthcare teams affect the way in which patient care is delivered, patients' perception of their medical treatment, and can ultimately help alleviate health disparities. For example, although basic modalities, such as interpreter services, are required, a more diverse physician workforce will include more culturally aware doctors who emphasize using skills learned from cultural competence training programs in patient care. Additionally, a diverse physician workforce would utilize a variety of resources while treating patients, such as community health workers, alternative and traditional healing practitioners, and family and community members. By using these treatment modalities, physicians show respect for different cultural perspectives, which could increase patients' trust in their providers. As a result, these patients may feel more comfortable communicating their concerns, which could help improve health outcomes and lead to a decrease in overall health disparities [22].

\section{Current Efforts to Support First Gen Medical Students}

In addition to pipeline programs at the undergraduate level, institutional awareness has evolved over the need to develop First Gen student-specific endeavors and campaigns at the graduate and professional school level. Examples of efforts undertaken by Albany Medical College, University of North Carolina at Chapel Hill School of Medicine, Stanford University School of Medicine, and Georgetown University School of Medicine are outlined in a recent publication by the AAMC [23]. These efforts are often organized by medical school deans, many of which are psychiatrists, and generally focus on identifying First Gen medical trainees and creating resources or services that connect and support First Gen community members [24]. Our academic institution, the David Geffen School of Medicine (DGSOM) at UCLA, has established First Gen programming to connect First Gen medical students, residents, and fellows with dedicated First Gen faculty members for mentorship. In addition, this programming helps medical trainees appreciate the unique life experiences of their First Gen faculty members. The program also provides medical trainees with strategies for self-preservation and well-being. Finally, First Gen medical trainees have the opportunity to network with members from other campus First Gen graduate chapters (e.g., School of Management and School of Law) and advocate for First Gen-specific concerns and issues at bimonthly First Gen Advisory Board meetings. Although these efforts are an important first step forward, much work remains in terms of addressing the pipeline to medical school, the institutional climate, and the necessary organizational changes that are tailored to the needs of First Gen individuals in medicine.

\section{First Gen Medical Students and Academic Psychiatry}

Psychiatrists are uniquely positioned to help recruit, retain, train, and support First Gen medical students since they have numerous opportunities to interact with this population. Prior research has found that psychiatry faculty members frequently serve as group facilitators for Doctoring courses [25]. Furthermore, psychiatrists often lead institutional wellness programming efforts and are involved in the provision of services that support the mental health and well-being of medical trainees [26, 27]. In our experience, psychiatrists often have leadership roles in the dean's office, provide clinical supervision, and serve as preceptorship mentors for trainees at all stages of their clinical training.

\section{Conclusion}

The experiential assets possessed by First Gen students make them valuable to medical schools, their peers, and future patients. By increasing outreach and research on this population's experiences in the transition from undergraduate work to medical school, we can better educate, recruit, and maximize the potential of all First Gen physicians. Such efforts will lead to a diverse physician workforce that is better equipped to provide culturally sensitive patient care and will potentially reduce health disparities in an increasingly diverse US patient population.

Acknowledgments The authors would like to thank Dr. Robert Bilder and Dr. Douglas Grbic for their editorial assistance. As a firstgeneration undergraduate student interested in a career in medicine, I would also like to thank my parents for their motivation - parents whose hands show me years of strenuous labor, but whose eyes show me their dreams and aspirations.

\section{Compliance with Ethical Standards}

Disclosures On behalf of all authors, the corresponding author states that there is no conflict of interest. 


\section{References}

1. Association of American Medical Colleges. The American Medical College Application Service. AMCAS 2018 Application: new questions. https://aamc-orange.global.ssl.fastly.net/production/ media/filer_public/7d/4c/7d4c5b3c-be52-4c93-b382$8 \mathrm{dcc} 9 \mathrm{ea} 7 \mathrm{ffd} 3 / 2018$ amcas new questions- fact sheet.pdf. Accessed 2 Sept 2019.

2. Ackerman-Barger K, Valderama Wallace C, Latimore D, Drake C. Stereotype threat susceptibility among minority health professions students. J Best Pract Health Prof Divers. 2016;9(2):1232-46.

3. Redford J, Hoyer KM. First-generation and continuing-generation college students: a comparison of high school and postsecondary experiences. Stats in Brief (NCES 2018-009). National Center for Education Statistics. 2017. https://nces.ed.gov/pubs2018/2018009. pdf. Accessed 29 Oct 2019.

4. U.S. Department of Education, National Center for Education Statistics. Citizenship status: percentage distribution of firstgeneration undergraduates by their citizenship status: 2007-08. https://nces.ed.gov/Datalab/TablesLibrary/TableDetails/8535? keyword=2012213\&rst=true. Accessed 24 Dec 2019.

5. Mason HRC, Winseman J, Marcellon R, Huamantla M, Ruiz C, Ayala EE. First-generation medical student wellness in the United States: a cross-sectional snapshot. J Best Pract Health Prof Divers. 2018;11(2):96-106.

6. Addams AN, Bletzinger RB, Sondheimer HM, White SE, Johnson LM. Roadmap to diversity: integrating holistic review practices into medical school admission processes. Association of American Medical Colleges 2010. https://store.aamc.org/downloadable/ download/sample/sample_id/195/. Accessed 27 Dec 2019.

7. Oldfield K. Humble and hopeful: welcoming first-generation poor and working-class students to college. About Campus. 2007;11(6): 2-12.

8. Afeli SA, Houchins TA, Jackson NS, Montoya J. First generation college students demographic, socio-economic status, academic experience, successes, and challenges at pharmacy schools in the United States. Curr Pharm Teach Learn. 2018;10(3):307-15.

9. Summer Health Professions Education Program. History. http:// www.shpep.org/about/history/. Accessed 30 Oct 2019.

10. Doby W, Dorr A. 1999-2000 Report on outreach programs, University of California, Los Angeles. UCLA. http://apep.gseis. ucla.edu/archive/1999-00/1999-2000AnnualReporttoUCOP.pdf. Accessed 23 Dec 2019.

11. UCLA Summer Health Professions Education Program (SHPEP). https://medschool.ucla.edu/apply/shpep. Accessed 30 Oct 2019.

12. Satterfield JM, Carney PA. Aligning medical education with the nation's health priorities: innovations in physician training in behavioral and social sciences. 2015. https://archive.ahrq.gov/ professionals/education/curriculum-tools/population-health/ satterfield.html. Accessed 28 Oct 2019.
13. Gift HC, Andersen RM, Davidson PL, Thind A. The pipeline program at the University of California, Los Angeles, School of Dentistry. J Dent Educ. 2009;73(2 suppl):S186-S198.

14. Grbic D, Sondheimer H. Personal well-being among medical students: findings from an AAMC pilot survey. Association of American Medical Colleges: Analysis in Brief. 2014;14(4):1-2.

15. Cataldi EF, Bennett CT, Chen X. First-generation students: college access, persistence, and postbachelor's outcomes. Stats in Brief (NCES 2018-421). National Center for Education Statistics. 2018. https://nces.ed.gov/pubs2018/2018421.pdf. Accessed 27 Dec 2019.

16. Skomsvold P. Profile of undergraduate students: 2011-12. (NCES 2015-167). National Center for Education Statistics. 2014. https:// files.eric.ed.gov/fulltext/ED581717.pdf. Accessed 26 Dec 2019.

17. Talamantes E, Mangione CM, Gonzalez K, Jimenez A, Gonzalez F, Moreno G. Community college pathways: improving the US physician workforce pipeline. Acad Med. 2014;89(12):1649-56.

18. Gomez LE, Bernet P. Diversity improves performance and outcomes. J Natl Med Assoc. 2019;111(4):383-92.

19. Saha S, Guiton G, Wimmers PF, Wilkerson L. Student body racial and ethnic composition and diversity-related outcomes in US medical schools. JAMA. 2008;300(10):1135-45.

20. Alvarado A, Spatariu A, Woodbury C. Resilience \& emotional intelligence between first generation college students and non-first generation college students. FOCUS on Colleges, Universities \& Schools. 2017;11(1):1-10.

21. Havlik S, Pulliam N, Malott K, Steen S. Strengths and struggles: first-generation college-goers persisting at one predominantly white institution. J Coll Stud Ret. 2017:1-23.

22. Brach C, Fraserirector I. Can cultural competency reduce racial and ethnic health disparities? A review and conceptual model. Med Care Res Rev. 2000;57(1):181-217.

23. Haskins J. Finding success as a first-generation medical student. Association of American Medical Colleges News 2019. https:// www.aamc.org/news-insights/finding-success-first-generationmedical-student. Accessed 5 Sept 2019.

24. Buckley PF. The medical school dean: leadership and workforce development. Acad Psychiatry. 2014;38(1):82-5.

25. Bourgeois JA, Ton H, Onate J, McCarthy T, Stevenson FT, Servis ME, et al. The doctoring curriculum at the University of California, Davis School of Medicine: leadership and participant roles for psychiatry faculty. Acad Psychiatry. 2008;32(3):249-54.

26. Chang E, Eddins-Folensbee F, Porter B, Coverdale J. Utilization of counseling services at one medical school. South Med J. 2013;106(8):449-53.

27. Baker K, Sen S. Healing medicine's future: prioritizing physician trainee mental health. AMA J Ethics. 2016;18(6):604-13.

Publisher's Note Springer Nature remains neutral with regard to jurisdictional claims in published maps and institutional affiliations. 